\title{
Repply: Integrative review of literature: nursing care to aged people with HIV
}

\author{
Rúbia de Aguiar Alencar' \\ ' Universidade Estadual de São Paulo, Faculdade de Medicina de Botucatu, \\ Departamento de Enfermagem. Botucatu-SP, Brasil
}

\section{Corresponding Author:}

Rúbia de Aguiar Alencar

E-mail: rubia@fmb.unesp.br

\section{Dear Editor,}

I would like to request clarification of the authors on the points raised in the article reading - Integrative review of literature: nursing care to aged people with $\mathrm{HIV}^{(1)}$.

The article quoted above quotes my article twice (one in Portuguese and another in English - References 25 and 30) and I see that this needs to be reviewed.

Another issue, which actually bothered me, was the quotations in the text that do not fit with what is in my $\operatorname{article}^{(2)}$. Here are two examples:

A retrospective and descriptive research carried out in Montevideo, Uruguai $\underline{(23)}$ also noted these data, identifying the total of admitted and hospitalized with an average age of 63 years and a similar percentage for both sexes $(53 \%$ men and $47 \%$ women). Other studies pointed out similar data ${ }^{(24-25)}$.

In the study I have developed, we did not study hospitalized patients, but the elderly patients living with HIV who were treated as outpatients.

"This way, the disease becomes common and there is no concerns on the use of condoms $\stackrel{(28)}{ }$. The assessed studies clarify that there is no groups of risk, only behaviors of risk ${ }^{(29-30) . " ~ I n ~ m y ~ s t u d y, ~ t h e ~ t h e o r e t i c a l ~ r e f e r e n c e ~}$ of vulnerability was used (this is explicit since the introduction of the work), which differs a lot from the concept of "behaviors of risk".

Without further ado, I avail myself of the opportunity to express my highest esteem.

Sincerely,

\section{REFERENCES}

1. Silva AG, Cavalcanti VS, Santos TS, Bragagnollo GR, Santos KS, Santos IMS, et al. Integrative review of literature: nursing care to aged people with HIV. Rev Bras Enferm [Internet]. 2018 [cited 2018 Jun 28];71( Suppl 2):884-92. Available from: http://dx.doi.org/10.1590/0034-7167-2017-0264

2. Alencar RA, Ciosak SI. Aids in the elderly: reasons that lead to late diagnosis. Rev Bras Enferm [Internet]. 2016 [cited 2018 Jun 28];69(6):1140-6. Available from: http://dx.doi.org/10.1590/0034-7167-2016-0370 


\section{Dear Mrs. Prof. Doctor Rúbia de Aguiar Alencar,}

We are here to clarify that the paragraph in question (third paragraph) on page $944^{(1)}$ discussed the gender relationship between the results of three different studies, in order to highlight the contradiction existing in the elderly man/woman relationship with HIV. In this sense, our interest, at that moment in the analysis, was not the level of attention to which the research participant was following up. The purpose of our article focused on nursing care for the elderly with HIV, regardless of the type of health service. Thus, in order to improve writing, we suggest that the last two sentences of the paragraph be rewritten as follows: "Regarding the patient's sex, we observed contradictory opinions. Some of the analyzed authors report there is an expressive number of infected men when compared to women; however, other researchers report that it is important to highlight that the difference in the ratio men/women has been decreasing ${ }^{(23)}$ and a third study the percentage of women is higher than that of men ${ }^{(24) "}$.

Regarding the mention of study number 30, when we deal with groups and behaviors of risk, we recognize the conceptual difference and the contributions brought by the theoretical reference of vulnerability. In this sense, we suggest excluding the reference number 30 by modifying it to: "It is considered that there are no groups of risk but behaviors and vulnerabilities ${ }^{(29) "}$ in accordance with reference 29 that addresses behaviors and vulnerabilities.

We appreciate the opportunity to reshape the essay by matching the references after review. We think there was confusion of versions between the authors and we apologize. We also apologize for the inconvenience mentioned by Mrs. Rúbia de Aguiar Alencar regarding the citation of her work and reiterate that at no time was this intention. We reaffirm our commitment to producing quality knowledge and wish to have fulfilled the request of the letter sent to the editor. We are available for further clarification, if necessary.

Sincerely,

\section{REFERENCE}

1. Silva AG, Cavalcanti VS, Santos TS, Bragagnollo GR, Santos KS, Santos IMS, et al. Integrative review of literature: nursing care to aged people with HIV. Rev Bras Enferm [Internet]. 2018 [cited 2018 Jun 28];71( Suppl 2):884-92. Available from: http://dx.doi.org/10.1590/0034-7167-2017-0264

Authors: Arayana Gomes da Silva, Viviane Siqueira Cavalcanti, Tâmyssa Simões dos Santos, Gabriela Rodrigues Bragagnollo, Karen da Silva Santos, Ivanilde Miciele da Silva Santos, Kristiana Cerqueira Mousinho, Cinira Magali Fortuna 